\title{
Caring for older patients with advanced chronic kidney disease and considering their needs: a qualitative study
}

Nwamaka D. Eneanya ${ }^{1,2^{*}}$ D, Allison K. Labbe ${ }^{3}$, Taylor L. Stallings ${ }^{2}$, Shananssa Percy ${ }^{4}$, Jennifer S. Temel ${ }^{5}$, Tamar A. Klaiman² and Elyse R. Park ${ }^{3}$

\begin{abstract}
Background: Older patients with advanced chronic kidney disease often do not understand treatment options for renal replacement therapy, conservative kidney management, and advance care planning. It is unclear whether both clinicians and patients have similar perspectives on these treatments and end-of-life care. Thus, the aim of this study was to explore clinician and patient/caregiver perceptions of treatments for end-stage renal disease and advance care planning.

Methods: This was a qualitative interview study of nephrologists $(n=8)$, primary care physicians $(n=8)$, patients ( $n=10, \geq 65$ years and estimated glomerular filtration rate $<20$ ), and their caregivers $(n=5)$. Interviews were conducted until thematic saturation was reached. Transcripts were transcribed using TranscribeMe. Using Nvivo 12, we identified key themes via narrative analysis.

Results: We identified three key areas in which nephrologists', primary care physicians', and patients' expectations and/or experiences did not align: 1) dialysis discussions; 2) dialysis decision-making; and 3) processes of advance care planning. Nephrologist felt most comfortable specifically managing renal disease whereas primary care physicians felt their primary role was to advocate for patients and lead advance care planning discussions. Patients and caregivers had many concerns about the impact of dialysis on their lives and did not fully understand advance care planning. Clinicians' perspectives were aligned with each other but not with patient/caregivers.

Conclusions: Our findings highlight the differences in experiences and expectations between clinicians, patients, and their caregivers regarding treatment decisions and advance care planning. Despite clinician agreement on their responsibilities, patients and caregivers were unclear about several aspects of their care. Further research is needed to test feasible models of patient-centered education and communication to ensure that all stakeholders are informed and feel engaged.
\end{abstract}

Keywords: Advance chronic kidney disease, Advance care planning, Dialysis decision-making

\footnotetext{
* Correspondence: Nwamaka.eneanya@pennmedicine.upenn.edu

${ }^{1}$ Renal-Electrolyte and Hypertension Division, Perelman School of Medicine, University of Pennsylvania, 307 Blockley Hall, 423 Guardian Drive, Philadelphia, PA 19104, USA

${ }^{2}$ Palliative and Advanced Illness Research Center, Perelman School of Medicine, University of Pennsylvania, Philadelphia, PA, USA

Full list of author information is available at the end of the article
}

\section{Background}

Chronic kidney disease (CKD) among older patients is common in the United States and the prevalence among those aged $\geq 65$ has increased from approximately 3 to $14 \%$ in the last two decades [1]. Among patients who ultimately develop end-stage renal disease (ESRD), many are referred by their nephrologists for educational

(c) The Author(s). 2020 Open Access This article is licensed under a Creative Commons Attribution 4.0 International License, which permits use, sharing, adaptation, distribution and reproduction in any medium or format, as long as you give appropriate credit to the original author(s) and the source, provide a link to the Creative Commons licence, and indicate if changes were made. The images or other third party material in this article are included in the article's Creative Commons licence, unless indicated otherwise in a credit line to the material. If material is not included in the article's Creative Commons licence and your intended use is not permitted by statutory regulation or exceeds the permitted use, you will need to obtain permission directly from the copyright holder. To view a copy of this licence, visit http://creativecommons.org/licenses/by/4.0/ The Creative Commons Public Domain Dedication waiver (http://creativecommons.org/publicdomain/zero/1.0/) applies to the data made available in this article, unless otherwise stated in a credit line to the data. 
sessions to learn about different treatment options such as dialysis. However, ESRD patient education programs tend to focus on modality type, vascular access, and care setting rather than on how the different treatment modalities may affect patient lifestyles and goals of care [24]. Few patients with advanced CKD are aware of treatment options such as conservative kidney management or advance care planning and seldom have an opportunity to discuss preferences with their clinicians or loved ones [5-7]. One recent study of older patients with advanced CKD and ESRD showed that many did not fully understand dialysis and perceived it as the only alternative to death [6].

Emerging models of care demonstrate that integration of palliative care within nephrology practices can help promote conservative kidney management and advance care planning and also improve patient satisfaction among older patients; however, implementation has proved to be challenging $[8,9]$. Previous research has demonstrated numerous clinician barriers to providing conservative kidney management and facilitating advance care planning including prognostic uncertainty, inconsistent collaboration between nephrologists and primary care physicians (PCP), and limited knowledge of ESRD treatment options [10-12]. Although there is some literature that explores perceptions of ESRD treatment and end-of-life care options among older patients with advanced CKD and ESRD, it is unclear whether their views are consistent with their clinicians [6, 1319]. To fill this knowledge gap, we sought to explore the alignment between clinician views of their responsibilities and patient clinical experiences via qualitative interviews with nephrologists, PCPs, patients, and caregivers regarding ESRD treatments and advance care planning.

\section{Methods}

\section{Study design and participant population}

We conducted this qualitative study between 3/2017 and 5/2018 at Massachusetts General Hospital in Boston, Massachusetts. Eligibility criteria included a convenience sample of PCPs and nephrologists who cared for older patients with advanced CKD (aged $\geq 65$ with estimated glomerular filtration rate $<20$ as defined by the CKD Epidemiology Collaboration for estimation of GFR) who were not on dialysis [20].

PCPs and nephrologists were recruited via email from primary care and nephrology clinics at Massachusetts General Hospital. All clinicians had a professional working relationship with N.D.E and all clinicians who were approached agreed to participate in the study. Written informed consent was subsequently obtained by the primary investigator (N.D.E, MD - nephrologist, female]). A telephone interview was then scheduled by A.K.L, (PhD - psychologist, female). A study coordinator (S.P,
BA - study coordinator, female) approached patients with advanced CKD and their caregivers on the day they were scheduled to receive in-person dialysis education from trained nurses in the outpatient nephrology clinic. None of the patients had a relationship with N.D.E. prior to recruitment. Out of 15 patients who were approached, 3 patients were not interested in the study. Twelve patients were consented, however 2 were withdrawn from the study as one was hospitalized and the other was lost to follow-up. Out of 10 enrolled patients, 5 patients had at least one caregiver who was interested in participating in the study. The study coordinator obtained written informed consent for all participants and scheduled the phone interview. All phone interviews took place in a quiet setting of the participant's choice. Patient and caregivers were interviewed separately. No other individuals were present during the phone interviews outside of the study participant and interviewer (A.K.L).

Investigative team members, all trained in qualitative methods, (N.D.E, A.K.L and E.R.P [PhD - psychologist, female]) developed both clinician and patient/caregiver semi-structured interview guides (See Additional file 1). Both guides were pilot tested among clinicians $(n=3)$ and patients $(n=5)$ and modified based on feedback prior to use in the study. All interviews were conducted and audiotaped by the same member of the investigative team (A.K.L). There were no field notes recorded during the interview as they were conducted by telephone. One clinician interview (nephrologist) was repeated due to audiotape malfunction. Prior to the interview, none of the participants knew A.K.L or had any knowledge of her research interests. Interviews were conducted among the convenience sample who represented varied perspectives. The Institutional Review Boards at Partners HealthCare and the University of Pennsylvania approved this study.

\section{Analyses}

TranscribeMe transcribed all audio recordings [21]. Transcripts were not returned to participants for comment or correction. Team members N.D.E, A.K.L, and T.A.K ( $\mathrm{PhD}$ - researcher trained in qualitative methods, female,) initially reviewed all the transcripts and created two codebooks (clinician and patient/caregiver) based on content that arose in the interviews. Transcripts were analyzed using Nvivo (version 12; QSR international, Melbourne, Australia). The codebook was iteratively revised after independent coding of initial transcripts by team members N.D.E, A.K.L, and T.L.S (MS - researcher trained in qualitative methods, female). After consensus meetings with all team members, the final codebooks were used to code the remaining transcripts (clinician transcripts - N.D.E and A.K.L; patient and caregiver transcripts - N.D.E and T.L.S). Emergent 
themes beyond those included in the interview guide were identified and discussed during the coding process. After reviewing all transcripts, themes were generally consistent across varied perspectives within the sample [22]. We determined that we had reached thematic saturation at this point [14, 22, 23]. Coding discrepancies were resolved via consensus. Participants did not provide feedback on findings.

\section{Results}

Mean time for clinician interviews (nephrologists $n=8$, primary care clinicians $n=8$ ) was $28 \mathrm{~min}$ and $3 \mathrm{~s} ; 12 \mathrm{~min}$ and $18 \mathrm{~s}$ for patient interviews $(n=10)$; and $11 \mathrm{~min}$ and $22 \mathrm{~s}$ for caregiver interviews $(n=5)$. Demographic data for all participants are displayed in Table 1 . We found a clear difference in alignment of experiences and expectations between clinicians and patients and their caregivers (Fig. 1).

\section{Themes}

Three major themes emerged from the data.

\section{Dialysis discussions}

Nephrologists and primary care clinicians felt that nephrologists' primary role was to manage all aspects of care specific to kidney disease and initiate dialysis discussions (Table 2). Several nephrologists remarked that they educated all of their patients about dialysis regardless of whether this would be beneficial to the patient. Consideration of lifestyle changes and quality of life were usually not strongly emphasized in dialysis discussions.

In terms of the role of PCPs, many PCPs and nephrologists commented that PCPs valued providing continuity of care in their patients' lives - especially in the setting of those who started dialysis and had to establish relationships with new nephrologists. Some PCPs and nephrologists felt the PCP's primary role was to ensure their patients understood how different treatments would impact their livelihood in addition to advocating for them as they navigated the healthcare system.

With regard to dialysis discussions, patients and their caregivers expressed positive sentiments about the quality of information that was provided and that they also trusted their clinicians' specific recommendations for dialysis. However, most only commented on being educated about the technical aspects of dialysis. These included modality and dialysis setting, access placement, and frequency of treatments. Many were not aware of alternatives to dialysis treatments and felt hopeless about their lack of options.

\section{Dialysis decision-making}

Often, nephrologists and PCPs felt that nephrologists were the most knowledgeable about which patients would not do well with dialysis therapy. Many nephrologists used frameworks that included age, and the presence of frailty and/or life-limiting illnesses when considering conservative kidney management (Table 3). Many nephrologists remarked that selecting treatments for renal disease based on these parameters was a central role in their clinical practice. In terms of the role of PCPs, nephrologists deferred to PCPs to integrate treatment decision making with patients' goals and also provide continuity of care.

However, although PCPs agreed that they should primarily help patients navigate their renal disease, several PCPs remarked that they struggled with ESRD treatment decisions for their older and frail patients with advanced CKD. For example, some PCPs felt that dialysis may not be the best treatment for their patients, but PCPs also

Table 1 Participant characteristics

\begin{tabular}{llll}
\hline & Clinicians $(n=16)$ & Patients $(n=10)$ & Caregivers $(n=5)$ \\
\hline Mean age \pm SD & $44.8 \pm 12$ & $73 \pm 5.9$ & $62.8 \pm 7.7$ \\
Female (\%) & $5(21)$ & $4(40)$ & $5(100)$ \\
Mean years of practice \pm SD & $14.8 \pm 11.7$ & - & $5(100)$ \\
Race (\%) & & $9(90)$ & 0 \\
White & $11(69)$ & $1(10)$ & 0 \\
Black & $1(6)$ & 0 & $5(100)$ \\
Asian & $4(25)$ & $10(100)$ & 0 \\
Non-Hispanic ethnicity (\%) & $14(88)$ & & $5(100)$ \\
Highest level of education (\%) & 0 & $2(20)$ & 0 \\
$\quad<$ High school diploma & 0 & $3(50)$ & 0 \\
High school diploma & 0 & 0 & \\
College degree & $16(100)$ & $30)$ & \\
Graduate degree & 0 &
\end{tabular}




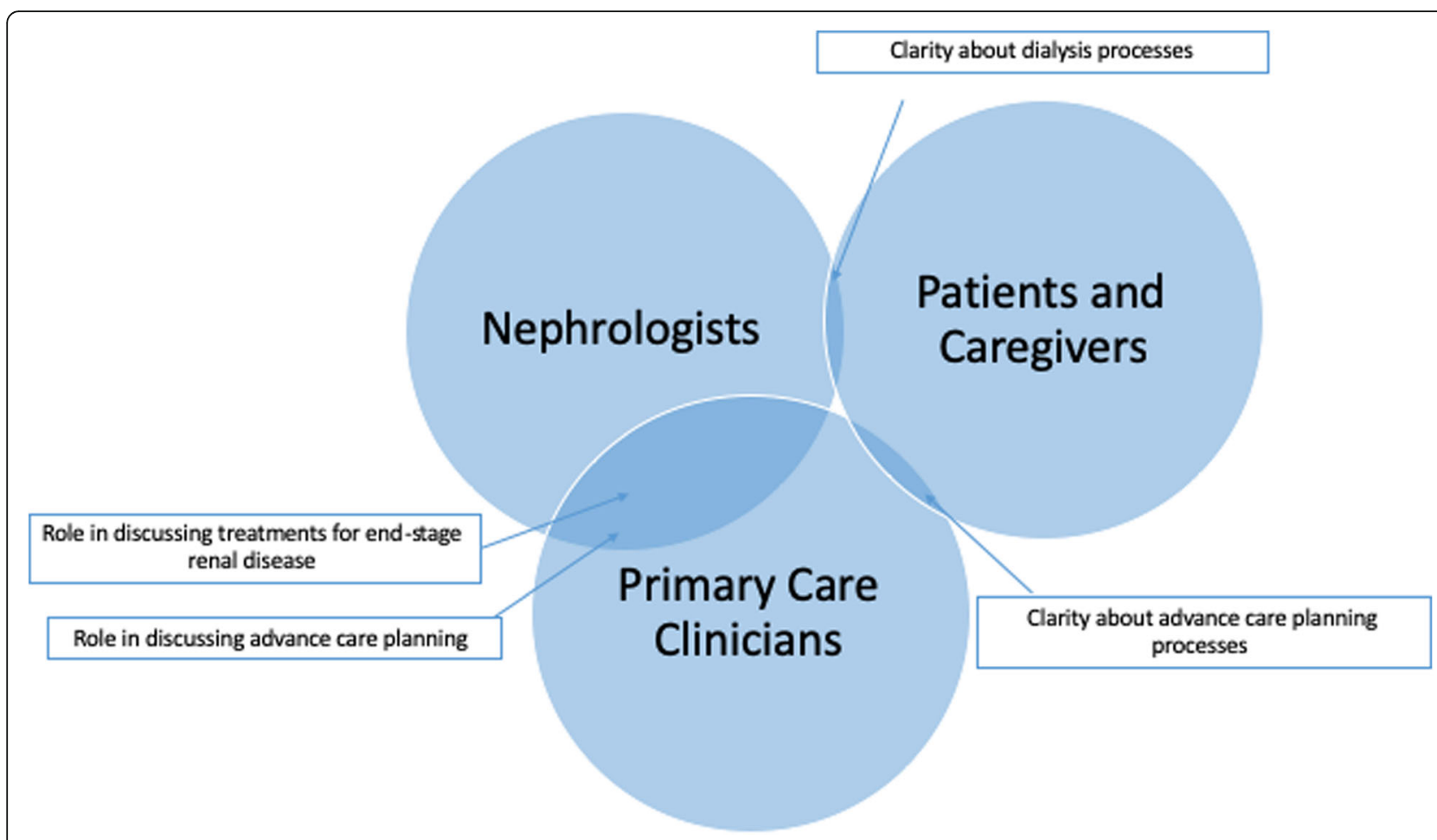

Fig. 1 Alignment of clinician and patient/caregiver expectations and experiences

did not feel that this decision was not for them to make. Many commented that deferring this decision to the nephrologist made the most sense. Others felt that decisions about dialysis or conservative kidney management should be made in conjunction with the nephrologist.

Although clinicians agreed about their respective roles in dialysis decision-making with their patients, patients and caregivers did not have a clear understanding of the implications of dialysis and expectations varied. For instance, many expressed concerns about the general effects of dialysis on their lifestyles. Other respondents were not sure what to anticipate from dialysis. Many expressed hopes that dialysis would make them feel better while others longed to live longer and normal lives.

\section{Processes of advance care planning}

Nephrologists felt that advance care planning discussions should primarily be led by PCPs, and many

Table 2 Dialysis discussions

\begin{tabular}{|c|c|c|}
\hline Nephrologists & Primary care physicians & Patients and caregivers \\
\hline $\begin{array}{l}\text { "So my job is to start the process and tell them how } \\
\text { to get more information on the time that we're not } \\
\text { together, and then continually follow up with them } \\
\text { until they feel good about the decision." (Clinician \#3) } \\
\text { "The nephrologist should } 100 \% \text { be the-- I think we } \\
\text { have the best sense of what that [dialysis] kind of } \\
\text { entails. Of course, if there are other physicians and } \\
\text { other people, part of the team, I think getting a sense } \\
\text { of the patient's overall goals and functional status and } \\
\text { comorbidities is very, very relevant, but this is } \\
\text { something that we will ultimately be prescribing and } \\
\text { managing. So, I think we should have the central role } \\
\text { in it." (Clinician \#2) } \\
\text { "Yeah... I bring it up in almost all cases. And then if } \\
\text { there are glaring issues that I think a patient would } \\
\text { suffer more than benefit from dialysis, I point those } \\
\text { out because most patients are aware that dialysis is an } \\
\text { option. So, I think never bringing it up is not part of } \\
\text { my practice because they're going to wonder about } \\
\text { it." (Clinician \#8) } \\
\text { "I have never had someone who refused to go } \\
\text { through dialysis for quality of life purposes." (Clinician } \\
\text { \#1) }\end{array}$ & $\begin{array}{l}\text { "I think the primary care doctor kind of understands } \\
\text { the most about the patient's social situation and I think } \\
\text { my role and a primary care doctor's role is to kind of } \\
\text { help patients through the initiation of dialysis, actually, } \\
\text { and through the kind of challenges of getting the } \\
\text { treatment." (Clinician \#6) } \\
\text { "So, I'll be thinking about their whole illness, their } \\
\text { whole life, how these things would fit in. And I can } \\
\text { help them understand kind of what life would be like if } \\
\text { they go on dialysis and how I would still be involved } \\
\text { in their care." (Clinician \#12) } \\
\text { "There are, however, other situations where I've had } \\
\text { this same patient for many, many years and now } \\
\text { maybe I referred them to nephrology, but I know the } \\
\text { patient better. I know the patient's family. I know the } \\
\text { patient's trajectory of how this has all developed and I } \\
\text { think in those settings, I mean, I think the primary care } \\
\text { doctor can always offer knowledge of the patient and } \\
\text { the patient's goals and contribute that to the } \\
\text { conversation." (Clinician \#13) }\end{array}$ & $\begin{array}{l}\text { "The nurse ... went over everything with us. They gave } \\
\text { my mom a little booklet, which was very good } \\
\text { information in it. She explained it would be three times } \\
\text { a week. We talked about a fistula, that her getting that, } \\
\text { and she did mention that my mom could do it at } \\
\text { home, but it would be four times a day and my } \\
\text { mother didn't want to do that." (Caregiver \#25) } \\
\text { "Only that they're going to be putting fluid into my } \\
\text { belly. It's an input and output, so you put in the fluid } \\
\text { and you take it out, and you put it in." (Patient \#23) } \\
\text { "I know dialysis is something that you have to-- I think } \\
\text { insurance only covers it for three days a week. And so, } \\
\text { you have to go every other day, and then you can't } \\
\text { miss it, really. And I guess that's about it, yeah." (Patient } \\
\text { \#18) } \\
\text { "I'm disappointed that-- I got to do what I got to do. } \\
\text { I don't have a choice." (Patient \#19) } \\
\text { "I don't know. I've never really thought about it. Well, } \\
\text { all I know is that I have kidney failure, and if you had } \\
\text { no kidneys, what are you going to do? You're just } \\
\text { going to die. So, the only alternative is dialysis." (Patient } \\
\text { \#31) }\end{array}$ \\
\hline
\end{tabular}


Table 3 Dialysis decision-making

\begin{tabular}{|c|c|c|}
\hline Nephrologists & Primary care clinicians & Patients and caregivers \\
\hline $\begin{array}{l}\text { "I mean, the typical patients who are not great } \\
\text { candidates typically have other illnesses that } \\
\text { would-- that are either so life-limiting, or would } \\
\text { kind of compromise the feasibility of doing dia- } \\
\text { lysis in them. And probably the one I come up } \\
\text { with the most is people with dementia." (Clin- } \\
\text { ician \#2) } \\
\text { "And so, for example, I would bring it up and if } \\
\text { the individual has multiple comorbidities." } \\
\text { (Clinician \#8) } \\
\text { "Again, because they [PCPs] usually have a } \\
\text { longer-standing relationship with the patient } \\
\text { that they can help basically negotiate what } \\
\text { would be the best decision-making at this stage } \\
\text { of the patient's clinical condition and at this } \\
\text { stage in the patient's life." (Clinician \#7) } \\
\text { "[PCPS] to, I guess be a sounding board. And if } \\
\text { the patient has questions or if the patient goes } \\
\text { to a primary care doctor and it doesn't seem } \\
\text { like they're getting what's going on, I'm hoping } \\
\text { that the primary care doctor sort of has their } \\
\text { ears open for that and can feed that back to } \\
\text { me, so we can get the patient more education." } \\
\text { (Clinician \#3) }\end{array}$ & $\begin{array}{l}\text { "And then I think yeah, I'm not the ultimate } \\
\text { decision maker, so trying to serve as the liaison } \\
\text { between the nephrologist and the patient if } \\
\text { there's any disagreement on what might be } \\
\text { best going forward." (Clinician \#10) } \\
\text { "I struggle with this [dialysis decision] because } \\
\text { I'm a primary care doctor... Well, I would say if I'm } \\
\text { not sure that they're going to ever need it, if I } \\
\text { don't have the clinical confidence that it's going } \\
\text { to be offered to them. If I don't think it's going } \\
\text { to be offered, I'm not going to start a } \\
\text { conversation about it. So, I guess, usually, the } \\
\text { reason that would really keep me from talking } \\
\text { about it would be the feeling that the } \\
\text { nephrologist is not going recommend it. Yeah." } \\
\text { (Clinician \#12) } \\
\text { "Yeah. You know, in the primary care setting ... } \\
\text { I think that often these discussions for the } \\
\text { average patient are sort of had serially, where } \\
\text { the patient goes and talks to a nephrologist, the } \\
\text { patient comes talks with the primary care } \\
\text { provider. I think that whenever there's some } \\
\text { more complicated decision-making process, for } \\
\text { instance dialysis is not clearly of benefit, it is } \\
\text { something the patient may opt against reason- } \\
\text { ably, then that often prompts a more directed } \\
\text { discussion with the nephrologist. And the logis- } \\
\text { tics often for folks require some discussion be- } \\
\text { tween primary care and nephrology as well." } \\
\text { (Clinician \#11) }\end{array}$ & $\begin{array}{l}\text { "How long it's going to be. That's my concern } \\
\text { is, is this going to be once I start it's going to } \\
\text { be forever?" (Patient \#20) } \\
\text { "Well, it affected me. I think of a lot of different } \\
\text { things. I feel as though I'm going to lose a lot } \\
\text { of my freedom. If I wanted to travel or } \\
\text { something, I'm concerned about that. There's a } \\
\text { lot of concerns that I don't see any real positive } \\
\text { outlook on." (Patient \#18) } \\
\text { "It's scary. You really don't know what to expect. } \\
\text { Hopefully, it will help her instead of do } \\
\text { nothing." (Caregiver \#25) } \\
\text { "That he's going to get sicker and issues could } \\
\text { happen. I read some different horror stories of } \\
\text { different dialysis centers. So, I just hope he gets } \\
\text { better and not worse." (Caregiver \#32) } \\
\text { "Well, I gain that I'm able to live normally, I } \\
\text { mean, to the extent where I have to go every } \\
\text { other day." (Patient \#18) } \\
\text { "They told me it would be-- help me out, make } \\
\text { me better, hopefully live longer." (Patient \#21) }\end{array}$ \\
\hline
\end{tabular}

Table 4 Processes of advance care planning

\begin{tabular}{|c|c|c|}
\hline Nephrologists & Primary care physicians & Patients and caregivers \\
\hline $\begin{array}{l}\text { "I usually kind of put that [advance care } \\
\text { planning] in the hands of the primary care } \\
\text { physician. I would say I think that's the cultural } \\
\text { norm for a variety of reasons that makes sense. } \\
\text { They theoretically are looking at the broader } \\
\text { scope of the patient. We tend to be sub- } \\
\text { specialists who are consulting. Someone referred } \\
\text { the patient to us for a pretty specific reason, } \\
\text { mainly kidney failure, or whatever, and so we try } \\
\text { to stay within our assigned role of that." (Clin- } \\
\text { ician \#2) } \\
\text { "I just don't feel comfortable and I don't-- I also } \\
\text { don't want to duplicate or maybe contradict if } \\
\text { the patient has already discussed this [advance } \\
\text { care planning] with a primary care physician or } \\
\text { some other providers. They come to see me for } \\
\text { nephrology care primarily, so I focus on } \\
\text { nephrology with patients. If somebody asks to } \\
\text { me to do this, I'd be happy to, but I don't } \\
\text { particularly do it-- actually, I've never done it." } \\
\text { (Clinician \#4) } \\
\text { "So yes, I have done some of that. Could I do } \\
\text { better? Certainly.... They're doing that more }\end{array}$ & $\begin{array}{l}\text { "I mean, often. I usually do it many times. I } \\
\text { mean, I see patients at annuals and follow ups. } \\
\text { And usually, at least at their annual, we talk } \\
\text { about some of these aspects." (Clinician \#13) } \\
\text { "Again, like I said before, having a relationship. } \\
\text { Again, I think primary care doctors are in the } \\
\text { situation where they have hopefully established } \\
\text { trusted relationships. I think the nephrologist, as } \\
\text { someone who's sort of seeing somebody for the } \\
\text { first time, it's always hard." (Clinician \#16) } \\
\text { "The family and the patient and me. And with } \\
\text { the backdrop of the nephrologist having given } \\
\text { me the information and possibly-- so if you're } \\
\text { asking should the nephrologist be the first } \\
\text { person to raise it that is often not the right } \\
\text { circumstance ..." (Clinician \#15) } \\
\text { "Absolutely. I think anybody who's going on } \\
\text { dialysis, especially late in life or with significant } \\
\text { comorbidities, it's a helpful trigger for doing } \\
\text { some advance care planning." (Clinician \#11) }\end{array}$ & $\begin{array}{l}\text { "Not really. My husband and I have talked, but } \\
\text { no one else has talked." (Patient \#21) } \\
\text { "We haven't done one yet, but because she } \\
\text { told us that because I'm his wife then I would } \\
\text { have a say in it." (Caregiver \#27) } \\
\text { "That was many years ago that I filled that out. } \\
\text { I've been in and out of the hospital for years. } \\
\text { I'm sure that it's just part of the process." } \\
\text { (Patient \#31) } \\
\text { "I guess if it has to be, it has to be done." } \\
\text { (Patient \#26) } \\
\text { "I think it's a necessity. People should know and } \\
\text { should have the right to go the way they want } \\
\text { to go." (Caregiver \#34) } \\
\text { "When you're at the point that you know } \\
\text { something like that is happening, I guess. If it } \\
\text { points that way, I would want to have it before } \\
\text { it was too late, I would say." (Patient \#33) } \\
\text { "At the doctor. At the kidney doctor, really. The } \\
\text { doctor I see really." (Patient \#20) } \\
\text { "Okay. And so where should this conversation } \\
\text { occur? In the kidney doctor's office ..." } \\
\text { (Caregiver \#27) }\end{array}$ \\
\hline
\end{tabular}
and more on an inpatient basis. I think the primary care doctors could do a better job because it's pretty consistent that our patients have not discussed that." (Clinician \#8) 
remarked that they did not feel comfortable leading these discussions (Table 4). Some felt that advance care planning discussions should be conducted in the setting of an interdisciplinary meeting that included the patient, caregivers, and the clinicians most involved in that patient's care.

PCPs agreed with nephrologists about the role of discussing advance care planning and many PCPs felt they should initiate and drive goals of care discussions. Some PCPs also remarked that conducting goals of care conversations in conjunction with nephrologists would be ideal. Some PCPs felt that discussions should occur before or at the same time as renal replacement therapy discussions.

In contrast to clinicians' clarity about the process of discussing advance care planning, many patients and caregivers had not discussed their end-of-life wishes with their clinicians. Some patients had discussed their preferences with their caregivers and had also completed advance directives. Of those who had completed a health care proxy or living will, many reported they had done so during a hospitalization or before an elective surgery. Regardless of why they completed the form, only a few remarked on the value of having someone speak on their behalf and honoring their wishes if they became incapacitated. Patients and their caregivers also desired goals of care discussions that were honest and included the chances of survival if they were to choose dialysis. Some felt that these discussions should occur earlier in the disease course - before the time dialysis would be needed. Several also described wanting to have discussions with their family members at their nephrologists' office or in their homes.

\section{Discussion}

Among nephrologists, primary care clinicians, older patients with advanced CKD and their caregivers, perspectives and expectations about ESRD treatments and advance care planning varied. Furthermore, although clinicians were mostly aligned on their respective roles with regard to communication and care delivery, patients and caregivers were unclear about several aspects of dialysis, alternatives to treatment, and advance care planning. Lastly, patients and caregivers specifically desired more information about treatment choices and advance care planning from their nephrologists.

In the United States, the infrastructure to effectively deliver nephrology care to older patients with advanced chronic kidney disease continues to evolve [24]. Conservative kidney management, which incorporates nondialytic therapy that aims to slow progression of disease and treat a wide range of symptoms, is an approach that many clinicians are still learning about $[5,25,26]$. We found that both nephrologists and PCPs agreed that nephrologists should take the initiative in determining which patients are eligible for dialysis. However, PCPs struggled with dialysis decisions that had been made for patients who they personally felt would not fare well. Our results are consistent with Parvez et al. who found that, compared to nephrologists, PCPs were less knowledgeable about conservative kidney management treatment effectiveness and less confident about selection of suitable candidates [10]. However, this study also showed that nephrologists had difficulty with determining which of their patients would benefit from conservative kidney management. Ladin et al., described the "interpretative" approach to conservative kidney management (e.g., nephrologists serve as a treatment decision navigator for patients) as the best example of shared decision-making given that patients' values and goals are incorporated into the process [27]. However, in this same study, a minority of nephrologists actually presented conservative kidney management as an option to their patients. As we found that PCPs felt strongly about guiding their patients through the decision-making process, a collaborative model in which both the PCP and nephrologist assume distinct roles (e.g., information provider and treatment decision navigator, respectively) could potentially improve ESRD decision-making for this patient population [12, 28-30].

Integrative models of primary and specialty care have also been described to improve the rates of goals of care discussions and advance care planning among seriously ill patients [31, 32]. In our study, nephrologists and PCPs felt that although advance care planning was an important aspect of care for their older patients, most believed that PCPs should lead these discussions. These findings counter work from O'Hare et al. where they found that among physicians from different specialties (e.g. nephrology, cardiology, primary care, etc.), there was an unclear understanding of who should carry out advance care planning [11]. We also found that the few patients and caregivers who had goals of care discussions or had completed advanced directives, had done so in an inpatient setting. However, a recent study showed that standard initiation of advance care planning in primary care practices was effectively implemented across a large integrated health care system using staff training and electronic medical record enhancements [33]. Notably, most clinicians in our study described primarily communicating about their shared patients through the electronic medical record or email. Therefore, structured primary care interventions that utilize telecommunication as an adjunct to in-person clinic visits could promote interdisciplinary collaboration and circumvent systemic barriers to advance care planning such as lack of time and fragmentation of care [11, 34-37]. 
Perhaps the most striking finding from our study was the lack of clarity about ESRD treatment options and subsequent effects on livelihood as well as advance care planning among patients and their caregivers. The majority of patients and their caregivers seemed confident only in their knowledge of the process of dialysis treatments and advance directive completion. In particular, older patients with advanced CKD have been shown to have knowledge gaps with regard to prognostic awareness and disease progression [17]. However, our findings showed that patients were also in need of more information about the direct effects of ESRD treatments on their quality of life and longevity. Patients and caregivers also desired more information from their nephrologists regarding advance care planning - especially in the setting of dialysis decisions. In one recent study of older adults with advanced CKD, patients described poor communication with their nephrologists about their disease as a source of worry about their future health and misconceptions about their illness [17]. Another study showed that skewed perceptions about ESRD and end-of-life treatments could lead to more intense care at the end of life for patients with kidney disease [14]. These findings, in addition to our own, highlight the need for improved communication between nephrologists, PCPs, and their patients to fulfill the psychosocial needs of patients in addition to technical information requests. Current clinician training programs on how to effectively conduct goals of care discussions with seriously ill patients with kidney disease show self-reported improvement and confidence in communication skills [38]. However, more research is needed to also evaluate the quality of communication and whether concerns regarding illness and treatment effects are adequately addressed among older patients and their caregivers.

This study has a few limitations. First, the modest sample size limits transferability of our findings to clinicians, patients, and caregivers in different settings. Second, although we reached thematic saturation, it is possible that we could have identified additional observations with more interviews. Third, conversations about ESRD treatments with patients and caregivers mostly centered around dialysis options and we were thus unable to glean insights into perspectives about nondialytic treatments. Lastly, as we only included nephrologists and PCPs, we were unable to make inferences about experiences and perceptions among other members of the health care team.

\section{Conclusions}

This is the first study to our knowledge to comprehensively examine experiences around ESRD treatments and advance care planning discussions between clinicians, patients with advanced CKD and their caregivers. Our findings identify an important tension between clinicians' perceptions of communication and care delivery and unmet needs of patients and their caregivers. Further research is needed to develop and implement collaborative models of care to holistically care for older patients with advanced CKD and improve understanding of conservative kidney management and advance care planning.

\section{Supplementary information}

Supplementary information accompanies this paper at https://doi.org/10. 1186/s12882-020-01870-1.

Additional file 1.

Abbreviations

CKD: Chronic kidney disease; ESRD: End-stage renal disease; PCP: Primary care physician

\section{Acknowledgements}

Not applicable.

\section{Prior presentations}

This work was presented in poster format at the American Society of Nephrology Annual Meeting in Washington D.C. on November 7, 2019

\section{Authors' contributions \\ TAK and ERP contributed equally to this manuscript. Research idea and study design: NDE, AKL, JST, ERP; data acquisition: NDE, AKL, SP; data analysis/ interpretation of data: NDE, AKL, TLS, TAK, ERP; preparation of manuscript: NDE, AKL, TLS, JST, TAK, ERP. Each author contributed important intellectual content during manuscript drafting or revision, accepts personal \\ accountability for the author's own contributions, and agrees to ensure that questions pertaining to the accuracy or integrity of any portion of the work are appropriately investigated and resolved. All authors have read and approved the manuscript.}

\section{Funding}

NDE is supported by NIH grant K23DK114526. The funder did not have a role in the design of the study, data collection, analysis, interpretation of data, or in writing the manuscript.

\section{Availability of data and materials}

The datasets used and/or analyzed during the current study are available from the corresponding author on reasonable request.

\section{Ethics approval and consent to participate}

The Institutional Review Boards at Partner's HealthCare and the University of Pennsylvania approved this study. The study PI and coordinator obtained written informed consent from all study participants.

\section{Consent for publication}

Not applicable.

\section{Competing interests}

The authors declare that they have no competing interests.

\section{Author details}

${ }^{1}$ Renal-Electrolyte and Hypertension Division, Perelman School of Medicine, University of Pennsylvania, 307 Blockley Hall, 423 Guardian Drive,

Philadelphia, PA 19104, USA. ${ }^{2}$ Palliative and Advanced Illness Research Center, Perelman School of Medicine, University of Pennsylvania, Philadelphia, PA, USA. ${ }^{3}$ Department of Psychiatry, Massachusetts General Hospital, Harvard Medical School, Boston, MA, USA. ${ }^{4}$ Division of Nephrology, Department of Internal Medicine, Massachusetts General Hospital, Harvard Medical School Center, Boston, MA, USA. ${ }^{5}$ Division of Hematology and 
Oncology, Department of Internal Medicine, Massachusetts General Hospital, Harvard Medical School, Boston, MA, USA.

\section{Received: 5 January 2020 Accepted: 25 May 2020}

Published online: 03 June 2020

\section{References}

1. Saran R, Robinson B, Abbott KC, Agodoa LYC, Bhave N, Bragg-Gresham J, Balkrishnan R, Dietrich X, Eckard A, Eggers PW, et al. US renal data system 2017 annual data report: epidemiology of kidney disease in the United States. Am J kidney Dis. 2018;71(3s1):A7.

2. Ribitsch W, Haditsch B, Otto R, Schilcher G, Quehenberger F, Roob JM, Rosenkranz AR. Effects of a pre-dialysis patient education program on the relative frequencies of dialysis modalities. Perit Dial Int. 2013;33(4):367-71.

3. Little J, Irwin A, Marshall T, Rayner H, Smith S. Predicting a patient's choice of dialysis modality: experience in a United Kingdom renal department. Am J Kidney Dis. 2001;37(5):981-6.

4. Golper T. Patient education: can it maximize the success of therapy? Nephrol Dial Transpl. 2001;16(Suppl 7):20-4.

5. Wong SPY, MCFarland LV, Liu CF, Laundry RJ, Hebert PL, O'Hare AM. Care practices for patients with advanced kidney disease who forgo maintenance Dialysis. JAMA Intern Med. 2019;179:305-13.

6. Karlin J, Chesla CA, Grubbs V. Dialysis or death: a qualitative study of older patients' and their families' understanding of kidney failure treatment options in a us public hospital setting. Kidney Med. 2019;1(3):124-30.

7. Eneanya ND, Wenger JB, Waite K, Crittenden S, Hazar DB, Volandes A, Temel JS, Thadhani R, Paasche-Orlow MK. Racial disparities in end-of-life communication and preferences among chronic kidney disease patients. Am J Nephrol. 2016;44(1):46-53.

8. Scherer JS, Harwood K, Frydman JL, Moriyama D, Brody AA, Modersitzki F, Blaum CS, Chodosh J. A descriptive analysis of an ambulatory kidney palliative care program. J Palliat Med. 2019;23:259-63.

9. Scherer JS, Wright R, Blaum CS, Wall SP. Building an outpatient kidney palliative care clinical program. J Pain Symptom Manag. 2018;55(1):108-116. e102.

10. Parvez S, Abdel-Kader K, Pankratz VS, Song MK, Unruh M. Provider knowledge, attitudes, and practices surrounding conservative Management for Patients with advanced CKD. Clin J Am Soc Nephrol. 2016;11(5):812-20.

11. O'Hare AM, Szarka J, McFarland LV, Taylor JS, Sudore RL, Trivedi R, Reinke LF, Vig EK. Provider perspectives on advance care planning for patients with kidney disease: whose job is it anyway? Clin J Am Soc Nephrol. 2016;11(5): $855-66$

12. Tam-Tham H, King-Shier KM, Thomas CM, Quinn RR, Fruetel K, Davison SN, Hemmelgarn BR. Prevalence of barriers and facilitators to enhancing conservative kidney Management for Older Adults in the primary care setting. Clin J Am Soc Nephrol. 2016;11(11):2012-21.

13. Ladin K, Lin N, Hahn E, Zhang G, Koch-Weser S, Weiner DE. Engagement in decision-making and patient satisfaction: a qualitative study of older patients' perceptions of dialysis initiation and modality decisions. Nephrol Dial Transpl. 2017;32(8):1394-401.

14. Ladin K, Buttafarro K, Hahn E, Koch-Weser S, Weiner DE. "End-of-life care? I'm not going to worry about that yet" health literacy gaps and end-of-life planning among elderly Dialysis patients. Gerontologist. 2018;58(2):290-9.

15. Tonkin-Crine S, Okamoto I, Leydon GM, Murtagh FE, Farrington K, Caskey F, Rayner H, Roderick P. Understanding by older patients of dialysis and conservative management for chronic kidney failure. Am J Kidney Dis. 2015; 65(3):443-50.

16. Bristowe K, Selman LE, Higginson IJ, Murtagh FEM. Invisible and intangible illness: a qualitative interview study of patients' experiences and understandings of conservatively managed end-stage kidney disease. Ann Palliat Med. 2019;8(2):121-9.

17. Selman LE, Bristowe K, Higginson IJ, Murtagh FEM. The views and experiences of older people with conservatively managed renal failure: a qualitative study of communication, information and decision-making. BMC Nephrol. 2019;20(1):38.

18. Saeed F, Sardar MA, Davison SN, Murad H, Duberstein PR, Quill TE. Patients' perspectives on dialysis decision-making and end-of-life care. Clin Nephrol. 2019;91(5):294-300.

19. Davison SN. End-of-life care preferences and needs: perceptions of patients with chronic kidney disease. Clin J Am Soc Nephrol. 2010;5(2):195-204.
20. Levey AS, Stevens LA, Schmid CH, Zhang YL, Castro AF 3rd, Feldman HI, Kusek JW, Eggers $P$, Van Lente $F$, Greene $T$, et al. A new equation to estimate glomerular filtration rate. Ann Intern Med. 2009;150(9):604-12.

21. TranscribeMe. https://www.transcribeme.com/tos. Accessed 2 Jan 2020.

22. Guest G, Namey E, Chen M. A simple method to assess and report thematic saturation in qualitative research. PLoS One. 2020;15(5):e0232076.

23. O'Hare AM, Szarka J, McFarland LV, Vig EK, Sudore RL, Crowley S, Reinke LF, Trivedi R, Taylor JS: "Maybe they Don't even know that I exist": challenges faced by family members and friends of patients with advanced kidney disease. Clin J Am Soc Nephrol 2017, 12(6):930-938.

24. Rosansky SJ, Schell J, Shega J, Scherer J, Jacobs L, Couchoud C, Crews D, McNabney M. Treatment decisions for older adults with advanced chronic kidney disease. BMC Nephrol. 2017;18(1):200.

25. O'Connor NR, Kumar P. Conservative management of end-stage renal disease without dialysis: a systematic review. J Palliat Med. 2012;15(2):22835

26. Harris DCH, Davies SJ, Finkelstein FO, Jha V, Donner JA, Abraham G, Bello AK, Caskey FJ, Garcia GG, Harden P, et al. Increasing access to integrated ESKD care as part of universal health coverage. Kidney Int. 2019;95(4s):S1s33.

27. Ladin K, Pandya R, Perrone RD, Meyer KB, Kannam A, Loke R, Oskoui T, Weiner DE, Wong JB. Characterizing approaches to Dialysis decision making with older adults: a qualitative study of nephrologists. Clin J Am Soc Nephrol. 2018;13(8):1188-96.

28. Diamantidis CJ, Powe NR, Jaar BG, Greer RC, Troll MU, Boulware LE. Primary care-specialist collaboration in the care of patients with chronic kidney disease. Clin J Am Soc Nephrol. 2011;6(2):334-43.

29. Lee L, Hillier LM, Locklin J, Lumley-Leger K, Molnar F. Specialist and family physician collaboration: insights from primary care-based memory clinics. Health Soc Care Commun. 2019;27(4):e522-33.

30. Tonkin-Crine S, Santer M, Leydon GM, Murtagh FE, Farrington K, Caskey F, Rayner H, Roderick P. GPs' views on managing advanced chronic kidney disease in primary care: a qualitative study. British J Gen Pract. 2015;65(636): e469-77.

31. Quill TE, Abernethy AP. Generalist plus specialist palliative care--creating a more sustainable model. N Engl J Med. 2013;368(13):1173-5.

32. Ahia $\mathrm{CL}$, Blais $\mathrm{CM}$. Primary palliative care for the general internist: integrating goals of care discussions into the outpatient setting. Ochsner J. 2014;14(4):704-11.

33. Rose BL, Leung S, Gustin J, Childers J. Initiating advance care planning in primary care: a model for success. J Palliat Med. 2019;22(4):427-31.

34. Totten AM, Womack DM, Eden KB, McDonagh MS, Griffin JC, Grusing S, Hersh WR. AHRQ Comparative Effectiveness Technical Briefs. In: Telehealth: Mapping the Evidence for Patient Outcomes From Systematic Reviews. Rockville: Agency for Healthcare Research and Quality (US); 2016.

35. Tieu C, Chaudhry R, Schroeder DR, Bock FA, Hanson GJ, Tung EE. Utilization of patient electronic messaging to promote advance care planning in the primary care setting. Am J Hospice Palliat Care. 2017;34(7):665-70.

36. Doorenbos AZ, Levy WC, Curtis JR, Dougherty CM. An intervention to enhance goals-of-care communication between heart failure patients and heart failure providers. J Pain Symptom Manag. 2016;52(3):353-60.

37. Lund S, Richardson A, May C. Barriers to advance care planning at the end of life: an explanatory systematic review of implementation studies. PLoS One. 2015;10(2):e0116629.

38. Cohen RA, Jackson VA, Norwich D, Schell JO, Schaefer K, Ship AN, Sullivan AM. A nephrology Fellows' communication skills course: an educational quality improvement report. Am J Kidney Dis. 2016;68(2):203-11.

\section{Publisher's Note}

Springer Nature remains neutral with regard to jurisdictional claims in published maps and institutional affiliations. 